Indian J. Anim. HIth. (2019), 58(2) -Special Issue: 53-70

DOI: https://doi.org/10.36062/ijah.58.2SPL.2019.53-70

Review Article

\title{
USE OF PESTICIDES IN AGRICULTURE AND EMERGENCE OF RESISTANT PESTS
}

\author{
R. K. KOLE* , K. ROY ${ }^{1}$, B. N. PANJA ${ }^{2}$, E. SANKARGANESH ${ }^{1}$ \\ T. MANDAL ${ }^{3}$ AND R. E. WOREDE ${ }^{4}$ \\ Department of Agricultural Chemicals \\ Bidhan Chandra Krishi Viswavidyalaya \\ Mohanpur - 741 252, Nadia, West Bengal, India
}

\begin{abstract}
Crop protection chemicals known as pesticides are playing a significant role to ensure food security. Besides controlling pests in agriculture, they are also used in human and animal health programmes. Development of resistant pests poses a real challenge towards the effectiveness of these toxic pesticides leading to their increased application associated with residual toxicity in food and environment. An estimated 954 pest species which include arthropods, weeds and plant pathogens have developed resistance against various types of pesticides, viz. insecticides, herbicides and fungicides. Resistance development in pest populations is influenced by biological, genetic and operational factors. Various mechanisms involved in resistance development in insects, microbes and weeds are discussed. The extent of insecticide, fungicide and herbicide resistance in various pest species is also highlighted. Effective pest and resistance management practices require understanding the factors influencing its development. The important role of Insecticide Resistance Action Committee (IRAC), Fungicide Resistance Action Committee (FRAC) and Herbicide Resistance Action Committee (HRAC) for resistance management is indicated. Strategies to mitigate the resistance development in conventional pesticides, use of Plant Incorporated Protectants (PIPs) and biopesticides as alternative to chemical pesticides along with some general recommendations are suggested for adoption.
\end{abstract}

Key words: Fungicide, Herbicide, Insecticide, Pest resistance, Resistance mechanism and management

\section{Introduction}

General: The use of agrochemicals like fertilizers and pesticides have become an

important component of modern agricultural systems during the last century to bring about a

*Corresponding Author

${ }^{1}$ Department of Agricultural Entomology, B.C.K.V., Mohanpur - 741 252, Nadia, W.B.

${ }^{2}$ Department of Plant Pathology, B.C.K.V., Mohanpur - 741 252, Nadia, W.B.

${ }^{3}$ Department of Crop Production, ICAR-Vivekananda Parvatiya Krishi Anusandhan Sansthan,

Almora-263 601, Uttarakhand

${ }^{4}$ Department of Chemistry, Dire-Dawa University-1362, Dire-Dawa, Ethiopia 
significant increase in crop yields (Alexandratos and Bruinsma, 2012). It has been estimated that about $35-45 \%$ crop production is lost due to inadequate crop protection measures against pest attack by insects, weeds and diseases. Global use of pesticides such as insecticides, acaricides, fungicides, rodenticides, herbicides and antibiotics for crop protection was approximately 2.72 million metric tons in 2012 (Atwood and Paisley-Jones, 2017). Europe is the major consumer of pesticides (about $45 \%$ ) followed by USA (25\%) and the rest of the world $(30 \%)$ including India. Among the pesticide classes, consumption of herbicides is maximum (about $47.5 \%$ ) followed by insecticides (29.5\%), fungicides $(17.5 \%)$ and only $5.5 \%$ is shared by other pesticide classes (Agarwal et al., 2015). Besides controlling pests in agriculture, pesticides are also used to control human and livestock disease vectors and also to prevent or control organisms affecting other human activities.

In India, the estimated losses in crop production due to pests attack are approximately US \$43 million. The maximum consumption of pesticides has been reported in cotton followed by paddy, wheat and sugarcane (Subash et al., 2017). Unlike the world trend, the Indian crop protection market is dominated by insecticides covering almost $60 \%$ of domestic crop protection chemicals (Devi et $a l ., 2017)$. Fungicides and herbicides are the largest growing segments accounting for $18 \%$ and $16 \%$, respectively of total crop protection chemicals market (Devi et al., 2017). The rate of consumption of pesticides in India is amongst the lowest in the world $(0.6 \mathrm{~kg} / \mathrm{ha})$ compared to $5-7 \mathrm{~kg} / \mathrm{ha}$ in UK and almost 20-30 times ( $13 \mathrm{~kg} / \mathrm{ha})$ in China
(Yadav and Dutta, 2019). Erstwhile Andhra Pradesh (Seemandhra and Telangana), Maharashtra, Uttar Pradesh, Punjab and Haryana are the states that accounted for 70 per cent of total pesticide consumption in India (Devi et al., 2017).

Sustainable crop protection is an essential component of present and future food security. But the continuous and extensive use of these pesticides over the last few decades has led to serious pest resistance which also resulted in pest resurgence. Development of pest resistance against a particular pesticide makes the crop protection product ineffective and thereby reducing the pest management options. In addition, the evolution of pesticide resistance leads to increased application of chemicals for crop protection (Foster et al., 1998) and causes significant implications in both human health and the environment due to residual toxicity of pesticides (Mondal et al., 2018; Biswas et al., 2019). Compared to the effectiveness of antibiotics to control human diseases due to evolution of resistant bacteria or other microbial strains (WHO, 2014), the control of crop pests is also threatened by the evolution of resistance against insecticides, fungicides and herbicides (Powles and Yu, 2010; Bass et al., 2015; Lucas et al., 2015).

Pest resistance: Pest resistance toward pesticides is a serious and an urgent global problem limiting the use of pesticides in pest control. Development of pest resistance has been a major factor influencing pest management strategies for more than half a century. The first incidence of insecticide resistance was reported almost 100 years ago 
(Melander, 1914). Thereafter, with the introduction of synthetic organic insecticides likeDDTs (dichlorodiphenyltrichloroethane), cyclodienes, etc. during 1940s, there was also a rapid increase in occurrence of insecticide resistance due to their extensive use. The increasing trend of insecticide resistance with the number of species and pesticidal products was increased over time. The resistance of weeds against herbicides and that of various disease causing organisms like fungi against fungicides have been reported during 1960s and 1970s. However, the cases of insecticide resistance were much more as compared to the cases of herbicide and fungicide resistance. The trend in resistance development in various pest organisms has been well reviewed by Sparks and Nauen (2015).

Resistance reported in mosquitoes in different countries made DDT ineffective in preventing malaria in those regions (Miller, 2004). Consequently, mosquito-borne diseases have become resurgent, largely because of the developed insecticide resistance in mosquito vectors and the drug resistance of pathogens (Nannan, 2015). The horn fly, Haematobia irritans L. (Diptera: Muscidae), an important parasites affecting cattle herds around the world exhibited widespread resistance against pyrethroid insecticides while resistance against organophosphate insecticides was not identified in any of the fly populations evaluated (Brito et al., 2019). Pest resistance to transgenic crops (which are genetically developed to defend themselves against some pests) have also been reported in $\mathrm{Bt}$ (Bacillus thuringiensis) maize (Gassmann et al., 2011). So far pest resistance to pesticides has been recorded in about 954 pest species worldwide which include arthropods (546 species), weeds (218 species) and plant pathogens (190 species) (Tabashnik et al., 2014).

\section{Development of pest resistance}

The evolution of resistance to pesticides, drugs and antibiotics by pests and pathogens is due to adaptation to changes in environmental conditions, especially to stress situations. The process of evolution of resistance in various pest organisms against pesticides is a major challenge for applied evolutionary biologists (Hendry et al., 2017; Gould et al., 2018). The process is rapid and widespread and difficult to counter in most cases once resistance is detectable. Therefore, resistance management practices advocate delaying the evolution of resistant traits before they become widespread. Such approaches can protect the effective period of a pesticide with long-term economic use (Edwards et al., 2014).

Resistance development in field populations is influenced by biological, genetic and operational factors. Amongst these, biological (like generation time, offspring number, and dispersal) and genetic (resistance gene, genotype and resistance alleles) factors are seldom influenced by human being. While the operational factors like chemistry and mode of action of the pesticide, method of treatment, time and dosage of application, etc. can be controlled (Sarwar and Salman, 2015).

Mechanism of insect resistance: The insects 
can develop resistant through involvement of one or more mechanisms, viz., Metabolic resistance, Altered target-site resistance, Target site insensitivity, Penetration resistance and Behavioral resistance (Karaagac, 2012). Metabolic resistance is the most common mechanism which detoxifies the toxicant quickly by utilizing internal enzyme systems like mono-oxygenases, mixed function oxidases, cytochrome P-450 dependent oxidases, hydrolases (esterases) and glutathione-S-transferase, etc. Altered target-site resistance mediates change in the structure of the site of toxic action in the insect. By target site insensitivity the insecticide penetrates the insect cuticle, but the target site become insensitive. Penetration resistance can protect insects from a wide range of insecticides. It happens when insects such as the housefly, Musca domestica can slowly absorb the chemicals into their bodies because their outer cuticle has developed with the barriers against the products. Behavioral resistance occurs when insects are able to evade contact with insecticides through avoidance.

Example of target site insensitivity is the reduced sodium channel sensitivity in nerve cell membranes which was observed in Musca domestica and P. xylostella to DDT and pyrethroid insecticides. This mode of resistance was termed knockdown resistance (kdr) (Ying et al., 2019). The kdr sodium channel gene mutation was detected in horn fly populations, and the super kdr sodium channel gene mutation was found in homozygous resistant $\mathrm{kdr}$ individuals (Brito et al., 2019).
Although a number of studies focussed to understand the biochemical mechanism responsible for reduced sensitivity, but resistance development is an evolutionary process. Organisms are capable to evolve genetic mechanisms to overcome stress conditions such as pest infestation or pesticide selection. Therefore, greater understanding of the evolutionary mechanisms would be more useful for assessment and management of resistance (Maclean et al., 2010; Neve et al., 2014). The gene amplification process contributes to the evolutionary progression of many organisms. However, the precise mechanism(s) of gene duplication contributing to pesticide resistance is limited (Jugulam and Gill, 2018). Pesticide resistance may be monogenic, conferred by a single gene or it may evolve as a polygenic quantitative trait, especially when pesticide dose is low. Monogenic resistance is often associated with pests that are exposed to high doses of pesticides (Groeters and Tabashnik, 2000). Therefore, evolution of resistance could be inferred from the increase in dose or concentration required to cause a given level of mortality across generations (Haridas and Tenhumberg, 2018).

A comparison of the resistance development processes in the three major pesticide groups, viz., insecticides, herbicides and fungicides revealed the involvement of some common evolutionary forces along with some important differences (Hawkins et al., 2019). Fungicide resistance evolved by point mutations in the target-site encoding genes; herbicide resistance evolved through selection of polygenic metabolic resistance from standing variation; and insecticide 
resistance evolves through a combination of standing variation and mutations in the target site or major metabolic resistance genes (Hawkins et al., 2019). For example, Ran has been reported as the deltamethrin resistance gene. Further studies indicated that Ran is also associated with the resistance to multiple pesticides including parathion, DDT, carbaryl, etc. Therefore, Ran may be considered as a potential molecular target gene for control of pesticide resistance (Bo et al., 2018).

Mechanism of disease resistance: Change in genetic makeup of a fungal pathogen is considered as the origin of fungicide resistance. The process of resistance development may be single-step or a discrete process including major gene resistance or it may be a multi-step or continuous process including minor gene resistance, positive and negative cross resistance and multiple resistance (Brent and Hollomon, 2007; Malandrakis et al., 2015).

Single step resistance is characterised by a sudden and marked loss of effectiveness of the fungicide as observed in several major groups of fungicides including benzimidazoles, phenylamides, dicarboximides, etc. A gradual recovery of sensitivity has been reported in Phytophthora infestans, the potato late blight pathogen, to phenylamide fungicides (Cooke et al., 2006). In such cases, resistance tends to return quickly if unrestricted use of the fungicide is resumed. Multistep resistance is defined as gradual decline in disease control and decrease in sensitivity of pathogen populations as developed by azole and 2-amino-pyrimidine fungicides (Brent and Hollomon, 2007). A somewhat different 'polygenic' process of genetic change is thought to underlie the 'quantitative' or 'multi-step' pattern of resistance. The best known and most studied example is cereal powdery mildews, which are rather hard to study genetically and some of the data are conflicting (Hollomon et al., 1984).

Positive cross resistance is a phenomenon where pathogen populations that develop resistance to one fungicide automatically and simultaneously become resistant to other chemically related fungicides with similar mechanism of fungi-toxicity. For example, pathogen strains that resist carbendazim are almost always highly resistant to other benzimidazole fungicides such as benomyl, thiophanate-methyl and thiabendazole (Chung et al., 2009). Negative cross resistance is the condition where a sensitive pathogen becomes resistant to a fungicide, automatically confers a change to sensitivity to other fungicides. This phenomenon is totally different from cross-resistance in its origin and mechanism, and is usually termed 'multiple resistance'. An example is the common occurrence of strains of Botrytis cinerea that have become resistant to benzimidazole, dicarboximide and many other fungicides (Chen et al., 2016). Resistance to multiple fungicides was observed in the field population of Venturia inaequalis (Chapman et al., 2011).

Many types of resistance mechanisms are known. These include alteration of the biochemical target; increased production of the target protein; developing an alternative metabolic pathway that bypasses the target site; metabolic breakdown of the fungicide; exclusion or expulsion of the fungicide through ATP-ase dependent transporter 
proteins (Brent and Hollomon, 2007; Hawkins and Fraaije, 2018).

The fungi can alter the target site as has been observed in methyl benzimidazole carbamates (MBC), phenylperroles and dicarboximides (Hawkins and Fraaije, 2018). Increased production of the target protein, viz., overexpression of tubulin protein in $\mathrm{MBC}$ resistant strain and overcountenance of $\mathrm{C} 14$ demethylase during sterol biosynthesis resistant strain were documented to nullify the toxic effect of the fungicide (Cools et al., 2012). Tolerance to Ustilago maydis to the antibiotic actimycin A was due to developing an alternative metabolic pathway that bypasses the target site. Metabolic breakdown of a fungicide often leads to its detoxification, while exclusion or expulsion of fungicide through ATP-ase dependent transporter proteins leading to fungicide resistance was correlated with levels of fungicide accumulation within fungal cells (Omrane et al., 2015).

Mechanism of weed resistance: Development of herbicide resistance in weeds may be genetic or it may be caused by herbicides from the selection of natural mutation or small pre-existing population of resistant plants (Duke et al., 1991). The selection pressure is the application of herbicides, which select for survival of members of the population that contain a mechanism imparting resistance to them. The term resistance should not be confused with tolerance. For example, wild oat (Phalaris minor) is described as tolerant to isoproturon because the species as a whole is naturally tolerant to this active ingredient (Powles and $\mathrm{Yu}, 2010)$. The herbicide resistance mechanisms may be grouped as: target site resistance, non target site resistance, cross resistance and multiple resistance (Heap and LeBaron, 2001; Sammons and Gaines, 2014; Yu and Powles, 2014).

Target site resistance (TSR) is generally due to a single or several mutations in the gene encoding the herbicide target enzyme which, in turn, decreases the affinity for herbicide binding to that enzyme. Most, but not all cases of resistance to herbicide Acetolactate synthase (ALS) inhibitors, Acetyl-CoA carboxylase (ACCase) inhibitors, triazine, dinitroaniline, etc. are due to modifications of the site of action of the herbicide. In addition, gene overproduction (amplification) is the most recently identified herbicide resistance mechanism. For example, EPSPS gene amplification correlates with glyphosate resistance in Amaranthus palmeri and Kochia scoparia and causes resistance by increasing the production of the target enzyme, effectively diluting the herbicide in relation to the target site (Gaines et al., 2010; Vila-Aiub et al., 2014; Godar et al., 2015).

Non target site resistance (NTSR) is caused by mechanisms that reduce the amount of herbicidal active compound before it can attack the plant. Reduced absorption (penetration) or altered translocation, increased herbicide sequestration or enhanced herbicide metabolism (detoxification) can cause resistance due to the restriction of herbicide movement where the herbicide does not reach its site of action in sufficient concentration to cause plant mortality. Active vacuolar or cell walls sequestration can keep the herbicide from 
the site of action leading to resistance. For example, vacuolar herbicide sequestration correlates with glyphosate resistance in Conyza canadensis, Lolium sp. etc. (Ge et al., 2010; 2012). The biochemical reactions that detoxify herbicides can be grouped into four major categories: oxidation, reduction, hydrolysis and conjugation.

Cross resistance (CR) means that a single resistance mechanism causes resistance to several herbicides. CR can be conferred by a single gene or by two or more genes influencing a single mechanism. There are two types of CR: target site cross resistance (TS CR) and non target site cross resistance (NTS CR). The most common type of CR is TS CR where an altered target site confers resistance to many or all of the herbicides that inhibit the same enzyme. For example, Trp 574 Leu amino acid substitution within the ALS gene was found in two populations of Cyperus iria after exposition to the herbicides, viz., bispyribac sodium, halosulfuron, imazamox and penoxsulam (Riar et al., 2015). On the other hand, NTS $\mathrm{CR}$ is the type of herbicide resistance in which a mechanism other than resistant enzyme target sites is involved (e.g. reduced absorption, translocation, or enhanced herbicide detoxification).

Multiple resistance is the phenomenon in which a weed is resistant to two or more herbicides having different mechanisms of action. Resistances of Lolium sp. populations to glyphosate and ACCase inhibitors, as well as resistance to glyphosate and ALS inhibitors were confirmed by multiple resistance (Sosnoskie et al., 2011). Multiple resistance can happen if a herbicide is used until a weed population displays resistance and then another herbicide is used repeatedly and the same weed population also becomes resistant to the second herbicide, and so on. Multiple resistance can also occur through the transfer of pollen (cross-pollination) between sexually compatible individuals that are carrying different resistant genes.

\section{Status on pest resistance}

Insect resistance scenario: Resistance in insects towards insecticides is a major problem since dates back, not only in agricultural insect pests but also insects of medical and veterinary importance, which invited for introduction of new insect control tools. At present, insecticide resistance is increased and has become a concern in wide range of insects and the problem extended to all major groups of insecticides including the new insecticides (Karaagac, 2012). Moreover, the resistance increases faster in greenhouse situations where insects reproduce rapidly.

The Colorado potato beetle, Leptinotarsa decemlineata, has been reported for resistance development against more than 50 insecticides while some populations of diamondback moth, Plutella xylostella against practically all available insecticides (Alyokhin et al., 2008; Haridas and Tenhumberg, 2018). Resistance to a number of insecticides has also been reported in various kinds of thrips infesting citrus, flower, onion, etc. (Shelton et al. 2006; Bielza et al., 2007). Later on resistance in tobacco thrips, Frankliniella fusca was also reported against neonicotinoid insecticides like imidacloprid and thiamethoxam, respectively making the thrips management strategies critical for 
sustainability of cotton production (Huseth et al., 2016; Darnell-Crumpton et al., 2018).

A number of sap-feeding insects, viz., Green Peach aphid, Myzus persicae; Cotton aphid, Aphis gossypii; Sweet potato whitefly, Bemisia tabaci; and Brown plant hopper, Nilaparvata lugens have a history of developing resistance to a number of insecticides. Later on many of these sapfeeding insect pests have also been reported to develop resistance against neonicotinoid insecticides (Sparks et al., 2013). Therefore, Sulfoxaflor, belonging to a new class of insecticides sulfoximines, has been introduced with high degree of efficacy against a number of sap-feeding insects, including those resistant to neonicotinoids and other insecticides (Sparks et al., 2013).

The status of physiological resistance and behavioural avoidance of mosquito vectors of human diseases to insecticides was reviewed (Chareonviriyaphap et al., 2013). Many mosquito populations have been reported in Thailand to develop resistance to all three classes of insecticidal active ingredients, viz., organochlorines, organophosphorus and pyrethroids. But, no pyrethroid resistance case was reported in Anopheles populations during 2000-2011. It was assumed that behavioral avoidance to insecticides might have played a significant role in reducing the selection pressure in developing and spreading of insecticide resistance (Chareonviriyaphap et al., 2013). Molecular basis for development of insecticide resistance is important for understanding the emerging problem of resistance development in mosquito vectors of human diseases and its management (Sweileh et al., 2016). A literature survey in
Cameroon revealed the insecticide resistance was highly prevalent in both Anopheles gambiae and A. funestus. Bendiocarb, DDT, deltamethrin and permethrin appeared to be the most affected compounds by resistance and some genes including P450 monooxygenase was associated with resistance development process (AntonioNkondjio et al., 2017).

The arthropod pest species differed significantly in time required to develop resistance. The median duration between the introduction of an insecticide and the first report of resistance was reported to be 66 generations. It was also reported that the highly-resistant arthropods did not evolve resistance faster than their relatives. The resistance development did not differ by the mode of action or year of introduction of the insecticide (Brevik et al., 2018).

Disease resistance scenario: At present more than 105 chemical groups comprising nonsystemic, systemic and antibiotic fungicides are used in disease control in agriculture (FRAC Code List, 2019). Even in the present day agricultural production system, they form one of the key components of integrated disease management. Systemic fungicides have a low toxicological profile for humans and other non-target organisms, become key components of disease management programmes, targeting to block a single biochemical step but prone to resistance development. Resistance of fungal pathogens to fungicides can be widespread and much worse or may be localized to a particular location or a few locations. The risk of resistance can vary greatly between regions where disease pressure and fungicide use are high and neighbouring areas where there is less disease or where yields are 
too low to support widespread fungicide use. For example, in Northern Europe several key cereal pathogens had developed resistance to a number of fungicide groups whereas in Southern Europe the same pathogens remained sensitive (Kuck, 2005).

Penicillium sp. causing storage rot of citrus was the plant pathogen against which resistance of aromatic hydrocarbons was recorded in 1960, after 20 years of its commercial release. There were a few sporadic records of fungicide resistance up to 1970 when only the non- systemic fungicides were used for crop protection. The time required for development of resistance (from the date of commercial release) for those non-systemic fungicides [like organomercurials, dodine and triphenyltins] was 15-40 years, where it was 5-10 years in case of some systemic fungicides and antibiotics [like dicarboximide, sterol biosynthesis inhibitors, phosphorothiolates and kasugamycin] and within 2 years in some other systemic fungicides [like benzimidazoles, 2- aminopyrimidines, phenylamides, quinone outside inhibitor and melanin bio-synthesis inhibitor] (Brent and Hollomon, 2007).

Most of the earlier fungicides such as copper, sulphur, dithiocarbamates, phthalimides, etc. have retained their full effectiveness in all their uses, despite their extensive and sometimes exclusive use over many years. The older generation fungicides rarely encounter resistance problems. Once they have penetrated the fungal cell, the older fungicides act as general enzyme inhibitors, affecting many target sites (hence they are sometimes called 'multi-site' inhibitors). They act selectively on fungi, rather than on plants and animals, because they penetrate and accumulate much more readily in fungi. Thus, just a single gene mutation can cause the target site to alter and become much less vulnerable to the fungicide (Steffens et al., 1996; Carter et al., 2014).

Biochemical evidence for polygenic resistance to azole fungicides indicated involvement of at least the five resistance mechanisms as discussed above; four mechanisms for quinone outside inhibitor and at least two mechanisms for methyl benzimidazole carbamate, anilinopyrimidine, phenyl pyrrole, dicarboximides, etc. (Hawkins and Fraaije, 2018). Among the different resistance mechanisms employed by fungi, an alteration to the biochemical target site is by far the most common mechanism.

Weed resistance scenario: The incidence of resistance against the herbicide 2, 4-D was observed in 1957, but the first confirmed report of herbicide resistance was recorded against triazine herbicide in common groundsel, Senecio vulgaris (Ryan, 1970). Worldwide herbicide resistance has been recorded in 259 weed species (151 dicots and 108 monocots) to 167 different herbicides in 93 crops distributed in 70 countries (Heap, 2019). The highest number of resistant weed biotypes has been observed against the herbicides belonging to ALS inhibitors, viz., imidazolinones, pyrimidinylthiobenzoates, sulfonylureas, triazolopyrimidines. The second most common group with resistant biotypes is the photosystem II inhibitors (primarily triazines). Dinitroaniline and triazine herbicides appear to have a medium level of inherent risk while chloroacetamides and 
synthetic auxins have a low inherent risk. A low inherent risk for resistance combined with extensive use can result in a higher risk potential. For example, the herbicide glyphosate was generally considered to have a low inherent risk. However, extensive use of glyphosate in absence of other weed control methods greatly increased the incidence of resistance. Heritable variability in the herbicide glyphosate sensitivity has been detected in some weed populations. Adaptive potential for herbicide resistance was assessed and evidence of directional selection for glyphosate insensitivity was reported for field resistance (Comont et al., 2019).

\section{Resistance management strategies}

Effective pest and resistance management practices require understanding the factors influencing its development including the genetics of resistance as well as ecological and environmental factors that affect the lifehistory of the pest. A major goal of insect resistance management (IRM) is to delay the evolution of resistance in an insect population against the pesticides it is exposed to. Therefore, there is a need for clear knowledge on the process of pest resistance for different classes of pesticides like herbicide, insecticide and fungicide, etc. for adoption of appropriate resistance management strategies (Buhler, 2019). Tabashnik et al. (2014) has provided various terminologies and their definitions related to pesticide resistance to facilitate understanding and management of resistance.

Resistance action committees: The Insecticide Resistance Action Committee (IRAC), an international association of crop protection companies, was established in 1984. It is focused to ensure long term effectiveness of insecticides, acaricides and traits through adoption of effective resistance management strategies (IRM) for sustainable agriculture and improved public health (IRAC, 2019). The most important function of IRAC is to develop the Mode of Action (MoA) classification of insecticidal products to provide up-to-date information on their modes of action which can serve as the basis for developing appropriate IRM strategies for crop protection and vector control. The IRAC also advocated for MoA labeling with IRM recommendations which have been adopted by many countries and reflected on the container labels of insecticides (Sparks and Nauen, 2015).

Fungicide Resistance Action Committee (FRAC) is a Specialist Technical Group of Crop Life International with the purpose to provide guidelines for management of fungicide resistance to prolong the effectiveness of fungicides (FRAC, 2019). Based on the risk of resistance development, fungicides has been classified by FRAC as high, medium to high, medium, low to medium, low and no risk fungicides. The global Herbicide Resistance Action Committee (HRAC) founded by the agrochemical industry helps by supporting efforts in the fight against herbicide-resistant weeds (HRAC, 2019).

Resistance management in conventional pesticides: Sustainable pest management strategy should include resistance management programme in association with alternative pest management strategies and integrated pest management (IPM) programs. To combat or slow down 
pesticide resistance in conventional pesticides, Environmental Protection Agency (EPA) of United States released two Pesticide Registration Notices (PRNs). The first one (PRN 2017-1) is the 'Guidance for Pesticide Registrants on Pesticide Resistance Management Labeling' applies to all conventional agricultural pesticides. The pesticide product labels should provide information for the users to minimize and manage pest resistance. The second one (PRN 2017-2) is the 'Guidance for Herbicide Resistance Management Labeling, Education, Training, and Stewardship' applies to herbicides only (US EPA, 2017).

\section{Regulation of plant incorporated} protectants: Application of plant genetic engineering technology in agriculture has developed some insect-resistant crops. Plantincorporated protectants (PIPs) are pesticidal substances produced by plants possessing necessary genetic constituents to produce the substance. The developed PIP crops such as cotton resistant to lepidopteran insects and maize resistant to lepidopteran as well as coleopteran insects have become popular in global agriculture leading to reduction in pesticide use (Brookes and Barfoot, 2005). Gatehouse (2008) have updated some developments in Bt strategy and selected alternative methods for engineering insect resistance in plants.

The PIP crops have genes for the production of endotoxin derived from the bacterium Bacillus thuringiensis (Bt)). Regulatory aspects on PIP crops include resistancemanagement as well as risk evaluations on human health and environment. EPA's regulation of PIPs includes the strategy for
IRM by reducing the selection pressure for Bt PIPs resistance through the use Non-PIP crops to serve as refuges (US EPA, 2017).

\section{Biopesticides and resistance management:} Biopesticides derived from biological sources, viz., bacteria, fungi, plants, etc. may be considered for resistance management programs in crop protection. Introduction of new pesticidal constituents including natural product-based pesticides are needed to combat the evolution of resistance to pesticides (Dayan et al., 2009). The use of bio-pesticides in integrated pest management could reduce pesticide use by 66 per cent in cotton and by 45 per cent in cabbage. Thus, bio-pesticides can play an important role in shifting the focus from chemical pesticides to reliable, sustainable and environment friendly options (Subash et al., 2017).

Bio-pesticides are becoming critical components of resistance management programs. Most of the bio-pesticides, especially the microbial products, have multiple modes of action and usually do not target a single site or gene. Therefore, a resistant pest with a single mode of action is unlikely to have cross resistance to a biopesticide with multiple modes of action or target sites. Thus, use of bio-pesticides may reduce or eliminate the development of resistance to pesticides (Dimock and Ockey, 2017).

Botanical pesticides are attractive alternatives to synthetic chemical insecticides for pest management derived from plants with insecticidal properties. They have several advantages over the synthetic pesticides due to the fact that they are cheap, easy to prepare, non-poisonous to human 
due to short life span and in most cases readily available and have more than one active ingredient which work synergistically making it difficult for pests to develop resistance (Tello et al., 2013).

General recommendations: Adoption of IPM strategies will help to prevent the increase in resistant pest types. Some of the general steps are as follows (US EPA, 2017):

- Apply recommended doses of pesticides: Recommended doses must be maintained to check the development of resistance and to get desired levels of pest control efficacy. With regard to multi-step resistance, low dose can enhance resistance development by favouring the survival of low-level resistant forms which would be inhibited by the full dose. Selection for resistance to triazole fungicides in barley powdery mildew was slowed down by lowering the fungicide concentration (Porras et al., 1990). Reducing the rate of triadimenol fungicide to its half level enhanced the development of resistance in grape powdery mildew in France.

- Use of pesticides alternatively or in mixture with different chemistry and modes of action: Laboratory studies showed that mixing of insecticides delays resistance mechanisms. The use of both mixtures and rotations of fungicides can delay the build-up of resistant variants. Application of mixtures of a phenylamide fungicide with mancozeb or mancozeb plus cymoxanil decreased the build-up of phenylamide resistance in Phytophthora infestans compared with phenylamide alone (Staub and Sozzi, 1984; Samoucha and Gisi, 1987).
Ideally, there should be more than one site of action to decrease the risk of evolution of resistance to a new pesticide. However, the development of new, highly active members of an existing pesticide class, which retain the same primary mechanism of action, may also be of some use in resistance management. The introduction of triazole fungicide prothioconazole has to some extent decreased problems of triazole resistance in cereal powdery mildews (Kuck and Mehl, 2004).

- Crop rotation to avoid the use of same pesticides, and Rotation of insecticides so that not all generations of the species are exposed to the same kind of chemical.

- Apply pesticides only when the pest population exceeds the economic threshold limit.

- Time of pesticide application should match the most vulnerable stage of the pest. Some of the resistance mechanism is poorly expressed in particular life stage of the pest. For example, both pyrethroid resistant and susceptible $H$. armigera neonates killed by fresh deposits of pyrethroids.

- Use of synergists to suppress detoxification mechanisms - applicable when resistance is governed by a single mechanism.

\section{Conclusion}

Sustainable crop protection plays a pivotal role for current and future food security to feed the anticipated nine billion world population by 2050 (Godfray et al., 2010). However, the effectiveness of the plant 
protection chemicals known as pesticides is threatened by the evolution of resistant pests and has become the major and alarming concern in the agrarian country. The evolution of pesticide resistance leads to increased application of chemicals for crop protection (Foster et al., 1998) and causes significant implications in both human health and the environment (Mondal et al., 2018; Biswas et al., 2019). Unfortunately, the specificity of the modern selective pesticides with the objective to reduce nontarget effects makes them vulnerable to develop resistance to the intended target pests (Hawkins et al., 2019). In order to overcome this scenario, it will be necessary to understand the processes that mediate the development of resistance and there is a need for empirical research on the mechanisms conferring resistance to novel chemical groups to combat the future threat. The

\section{REFERENCES}

Agarwal A, Prajapati R, Singh OP, Raza SK and Thakur LK, 2015. Pesticide residue in water - a challenging task in India. Environ Monit Assess, 187(54): 1-21, doi: 10.1007/s10661015-4287-y

Alexandratos N and Bruinsma J, 2012. World agriculture towards 2030/2050: the 2012 revision. ESA Working paper No. 12-03, FAO, Rome

Alyokhin A, Baker M, Mota-Sanchez D, Dively G and Grafius E, 2008. Colorado potato beetle resistance to insecticides. Am J Potato Res, 85: $395-413$

Antonio-Nkondjio C, Sonhafouo-Chiana N, Ngadjeu CS, Doumbe-Belisse P, Talipouo A et al., 2017. Review of the evolution of insecticide resistance in main malaria vectors in Cameroon from 1990 to 2017. Parasit Vectors, 10: 472, doi: 10.1186/s13071-017-2417-9 importance of integrated pest management need to be revisited along with alternatives to chemical pesticides, especially the use of bio-pesticides should be emphasized in combination with other approaches such as insect or disease resistant crop varieties. Regulatory measures in the use of conventional chemical pesticides may also be adopted for mitigating the pesticide resistance.

\section{ACKNOWLEDGEMENT}

The authors express their sincere gratitude to the Faculty of Agriculture, Bidhan Chandra Krishi Viswavidyalaya for providing the academic support for preparation of this manuscript; and also convey their sincere thanks to the Editor, Indian Journal of Animal Health for kindly inviting for this contribution.

Atwood D and Paisley-Jones C, 2017. Pesticides Industry Sales and Usage 2008-2012 Market Estimates. US Environmental Protection Agency, Washington, DC

Bass C, Denholm I, Williamson MS and Nauen R, 2015. The global status of insect resistance to neonicotinoid insecticides. Pestic Biochem Physiol, 121: 78-87

Bielza P, Quinto V, Contreras J, Torné M, Martín A et al., 2007. Resistance to spinosad in the western flower thrips, Frankliniella occidentalis (Pergande), in greenhouses of south-eastern Spain. Pest Manag Sci, 63: 682-687

Biswas S, Mondal R, Mukherjee A, Sarkar M and Kole RK, 2019. Simultaneous determination and risk assessment of fipronil and its metabolites in sugarcane, using GC-ECD and 
confirmation by GC-MS/MS. Food Chem, 272: 559-567, doi: 10.1016/ j.foodchem.2018.08.087

Bo Q, Chen L, Liu Y, Chang C, Ying Xet al., 2018. Analysis of Ran related to pesticide resistance in Drosophila Kc cells. Gene, 663: 131-137, doi: https://doi.org/10.1016/ j.gene.2018.04.031

Brent KJ and Hollomon DW, 2007. Fungicide resistance in crop pathogens: How can it be managed? FRAC Monograph No. 1, $2^{\text {nd }}$ Revised Edn., Fungicide Resistance Action Committee (FRAC), Croplife International, Brussels, Belgium, pp56

Brevik K, Schoville SD, Mota-Sanchez D and Chen YH, 2018. Pesticide durability and the evolution of resistance: A novel application of survival analysis. Pest Manag Sci, 74: 1953-1963, doi: 10.1002/ps.4899

Brito LG, Barbieri FS, Rocha RB, Santos APL, Silva RR, et al., 2019. Pyrethroid and organophosphate pesticide resistance in field populations of horn fly in Brazil. Med Vet Entomol, 33: 121-130, doi: 10.1111/ mve. 12330

Brookes G and Barfoot P, 2005. GM crops: the global economic and environmental impact: the first nine years 1996-2004. AgBio Forum, 8: 15

Buhler W, 2019. Introduction to Pesticide Resistance. Pesticide Environmental Stewardship. Available in https:// www.pesticidestewardship.org/resistance/ [10 Oct, 2019]

Carter HE, Fraaije BA, West JS, Kelly SL, Mehl A et al., 2014. Alterations in the predicted regulatory and coding regions of the sterol 14a-demethylase gene (CYP51) confer decreased azole sensitivity in the oilseed rape pathogen Pyrenopeziza brassicae. Mol Plant Pathol, 15: 513-522
Chapman KS, Sundin GW and Beckerman JL, 2011. Identification of resistance to multiple fungicides in field populations of Venturia inaequalis. Plant Dis, 95: 921-926

Chareonviriyaphap T, Bangs MJ, Suwonkerd W, Kongmee M, Corbel V et al., 2013. Review of insecticide resistance and behavioral avoidance of vectors of human diseases in Thailand. Parasit Vectors, 6: 280, doi:10.1186/1756-3305-6-280. Available in http://www.parasitesandvectors.com/ content/6/1/280

Chen SN, Luo CX, Hu MJ and Schnabel G, 2016. Fitness and competitive ability of Botrytis cinerea isolates with resistance to multiple chemical classes of fungicides. Phytopathology, 106: 997-1005

Chung WH, Chung WC, Ting PF, Ru CC, Huang HC et al., 2009. Nature of Resistance to Methyl Benzimidazole Carbamate Fungicides in Fusarium oxysporum f. sp. lilii and $F$. oxysporum $\mathrm{f}$. sp. gladioli in Taiwan. J Phytopathol, 157: 742-747

Comont D, Hicks H, Crook L, Hull R, Cocciantelli E et al., 2019. Evolutionary epidemiology predicts the emergence of glyphosate resistance in a major agricultural weed. New Phytol, 223: 1584-1594, doi: 10.1111/ nph. 15800

Cooke LR, Carlisle DJ, Donaghy C, Quinn M, Perez FM et al., 2006. The Northern Ireland Phytophthora infestans population 19982002 characterised by genotypic and phenotypic markers. Plant Pathol, 55: 320330

Cools HJ, Bayon C, Atkins S, Lucas JA and Fraaije BA, 2012. Overexpression of the sterol 14ademethylase gene (MgCYP51) in Mycosphaerella graminicola isolates confers a novel azole fungicide sensitivity pheno-type. Pest Manag Sci, 68: 1034-1340 
Darnell-Crumpton C, Catchot AL, Cook DR, Gore J, Dodds DM et al., 2018. Neonicotinoid insecticide resistance in tobacco thrips (Thysanoptera: Thripidae) of Mississippi. Jo Eco Ent, 111(6): 2824-2830, doi: 10.1093/ jee/toy 298

Dayan FE, Cantrell CL and Duke SO, 2009. Natural products in crop protection. Bioorg Med Chem, 17: 4022-4034, doi: 10.1016/ j.bmc.2009.01.046

Devi PI, Thomas J and Raju RK, 2017. Pesticide consumption in India: A spatiotemporal analysis. Agril Econ Res Rev, 30(1): 163172, doi: 10.5958/0974-0279.2017.00015.5

Dimock M and Ockey S, 2017. Resistance Management: A Critical Role for Biopesticides. CAPCA Advisor, Certis USA, $42-43$

Duke SO, Christy AL, Hess FD and Holt ZS, 1991. Herbicide- Resistant Crops. Comments from CAST 1991-1. Council of Agricultural Science and Technology, Ames, I.A

Edwards CB, Jordan DL, Owen MD, Dixon PM, Young BG et al., 2014. Benchmark study on glyphosate-resistant crop systems in the United States. Economics of herbicide resistance management practices in a 5 year field-scale study. Pest Manag Sci, 70: 19241929

Foster SP, Denholm I, Harling ZK, Moores GD and Devonshire AL, 1998. Intensification of insecticide resistance in UK field populations of the peach-potato aphid, Myzus persicae (Hemiptera: Aphididae) in 1966. Bull Entomol Res, 88: 127-130

FRAC Code List, 2019. Fungal control agents sorted by cross resistance pattern and mode of action (including FRAC Code numbering), Fungicide Resistance Action Committee (FRAC). Available in https:// www.frac.info/publications [03 Nov, 2019]
FRAC, 2019. Fungicide Resistance Action Committee. Available in http:// www.frac.info [03 Nov, 2019]

Gaines TA, Zhang W, Wang D, Bukun B, Chisholm ST et al., 2010. Gene amplification confers glyphosate resistance in Amaranthus palmeri. Proc Natl Acad Sci, 107(3): 10291034

Gassmann AJ, Petzold-Maxwell JL, Keweshan RS and Dunbar MW, 2011. Field-evolved resistance to $\mathrm{Bt}$ maize by western corn rootworm. PLos ONE 6: e22629

Gatehouse JA, 2008. Biotechnological prospects for engineering insect-resistant plants. Plant Physiol, 146: 881-887, doi: www.plantphysiol.org/cgi/doi/10.1104/ pp.107.111096

Ge X, D’Avignon DA, Ackerman JJH, Collavo A, Sattin M et al., 2012. Vacuolar glyphosate sequestration correlates with glyphosate resistance in ryegrass (Lolium spp.) from Australia, South America, and Europe: A 31P NMR investigation. J Agril Food Chem, 60: 1243- 1250

Ge X, D'Avignon DA, Ackermana JJH and Sammons RD, 2010. Rapid vacuolar sequestration: The horseweed glyphosate resistance mechanism. Pest Manag Sci, 66: $345-348$

Godar AS, Stahlman PW, Jugulam M and Dille JA, 2015. Glyphosate Resistant Kochia (Kochia scoparia) in Kansas: EPSPS gene copy number in relation to resistance levels. Weed Sci, 63: 587595

Godfray HCJ, Beddington JR, Crute IR, Haddad L, Lawrence D et al., 2010. Food security: the challenge of feeding 9 billion people. Science, 327: 812-818

Gould F, Brown ZS and Kuzma J, 2018. Wicked evolution: can we address the sociobiological dilemma of pesticide resistance? Science, 360: 728-732 
Groeters FR and Tabashnik BE, 2000. Roles of selection intensity, major genes, and minor genes in evolution of insecticide resistance. J Econ Entomol, 93(6): 1580-1587

Haridas CV and Tenhumberg B, 2018. Modeling effects of ecological factors on evolution of polygenic pesticide resistance. J Theo Biol, 456: 224-232, doi: https://doi.org/10.1016/ j.jtbi.2018.07.034

Hawkins NJ and Fraaije BA, 2018. Fitness penalties in the evolution of fungicide resistance. Ann Rev Phytopathol, 56: 339-360

Hawkins NJ, Bass C, Dixon A and Neve P, 2019. The evolutionary origins of pesticide resistance. Biol Rev, 94: 135-155, doi: $10.1111 /$ brv. 12440

Heap I and LeBaron H, 2001. Introduction and overview of resistance. In: Herbicide Resistance in World Grains (Powles SB, Shanel DL, eds.). Boca Raton, Florida, CRC Press, pp1-22

Heap I, 2019. The international Survey of Herbicide Resistant Weeds. Available in http:// www.weedscience.org/ [7 Nov, 2019]

Hendry AP, Gotanda KM and Svensson EI, 2017. Human influences on evolution, and the ecological and societal consequences. Philos Trans R Soc of Lon B Biol Sci, 372: 20160028, doi: 10.1098/rstb.2016.0028

Hollomon DW, Butters J and Clark J, 1984. Genetic control of triadimenol resistance in barley powdery mildew. Proceedings of British Crop Protection Conference, Pests and Diseases. 2: 477-482

HRAC, 2019. Herbicide Resistance Action Committee. Available in http:// www.hrac.global.com [03 Nov, 2019]

Huseth AS, Chappell TM, Langdon K, Morsello SC, Martin S et al., 2016. Frankliniella fusca resistance to neonicotinoid insecticides: an emerging challenge for cotton pest management in the eastern United States. Pest Manag Sci, 72: 1934-1945

IRAC, 2019. Insecticide Resistance Action Committee. Available in http:// www.iraconline.org [03 Nov, 2019]

Jugulam M and Gill BS, 2018. Molecular cytogenetics to characterize mechanisms of gene duplication in pesticide resistance. Pest Manag Sci, 74: 22-29 [doi: 10.1002/ps.4665]

Karaagac SU, 2012. Insecticide Resistance. In: Insecticides - Advances in Integrated Pest Management (Perveen F, ed), ISBN: 978953-307-780-2, InTech. Available in http:// www.intechopen.com/books/insecticidesadvances-in-integrated-pest-management/ insecticideresistance [03 Nov, 2019]

Kuck KH and Mehl H, 2004. Prothioconazole: sensitivity profile and anti-resistance strategy. Pflanzenschutz-Nachrichten Bayer, 57: $225-236$

Kuck KH, 2005. Fungicide resistance management in a new regulatory environment. In: Modern fungicides and anti-fungal compounds IV (Dehne HW, Gisi U, Kuck KH, Russell PE and Lyr H, eds). BCPC, Alton (UK), pp35-43

Lucas JA, Hawkins NJ and Fraaije BA, 2015. The evolution of fungicide resistance. Adv in Appl Microbiol, 90: 29-92

Maclean RC, Hall AR, Perron GG and Buckling A, 2010. The population genetics of antibiotic resistance: integrating molecular mechanisms and treatment contexts. Nature Reviews. Genetics, 11: 405-414

Malandrakis AA, Apostolidou ZA, Markoglou A and Flouri F, 2015. Fitness and crossresistance of Alternaria alternate field isolates with specific or multiple resistance to single site inhibitors and mancozeb. Eur J Plant Pathol, 142: 489-499 
Melander AL, 1914. Can insects become resistant to sprays? J Econ Entomol, 7: 167-173

Miller GT, 2004. Sustaining the Earth. $6^{\text {th }}$ Edn. Thompson Learning Inc., Pacific Grove, California, pp211-216

Mondal R, Mukherjee A, Biswas S and Kole RK, 2018. GC-MS/MS determination and ecological risk assessment of pesticides in aquatic system: A case study in Hooghly River basin in West Bengal, India. Chemosphere, 206, 217-230, doi: 10.1016/ j.chemosphere.2018.04.168

Nannan L, 2015. Insecticide resistance in mosquitoes: impact, mechanisms, and research directions. Ann Rev Entomol, 60(1): 537-559

Neve P, Busi R, Renton M and Vila-Aiub MM, 2014. Expanding the eco-evolutionary context of herbicide resistance research. Pest Manag Sci, 70: 1385-1393

Omrane S, Sghyer H, Audeon C, Lanen C, Duplaix $\mathrm{C}$ et al., 2015. Fungicide efflux and the MgMFS1 transporter contribute to the MDR phenotype in Zymoseptoria tritici field isolates. Environ Microbiol, 17: 2805-2823

Porras L, Gisi U and Staehle Csech U, 1990. Selection dynamics in triazole treated populations of Erysiphe graminis. Bringhton Crop Protection Conference, Pests and Diseases, 3: 1163-1168

Powles SB and Yu Q, 2010. Evolution in action: plants resistant to herbicides. Ann Rev of Plant Biol, 61: 317-347

Riar DS, Tehranchian P, Norsworthy JK, Nandula V, McElroy S et al., 2015. Acetolactate synthase inhibiting, herbicide resistant rice flatsedge (Cyperus iria): Cross resistance and molecular mechanism of resistance. Weed Sci, 63: 748757
Ryan GF, 1970. Resistance of common groundsel to simazine and atrazine. Weed Sci, 18: 614616

Sammons RD and Gaines TA, 2014. Glyphosate resistance: State of knowledge. Pest Manag Sci, 70: 13671377

Samoucha Y and Gisi U, 1987. Use of two or three way mixtures to prevent build-up of resistance to phenylamide fungicides in Phytophthora and Plasmopara. Phytopathology, 77: 1405-1409

Sarwar M and Salman M, 2015. Insecticides resistance in insect pests or vectors and development of novel strategies to combat its evolution. Int J Bioinfo Biomed Eng, 1: 344-351

Shelton AM, Zhao JZ, Nault BA, Plate J, Musser FR et al., 2006. Patterns of insecticide resistance in onion thrips (Thysanoptera: Thripidae) in onion fields in New York. J Econ Entomol, 99: 1798-1804

Sosnoskie LM, Kichler JM, Wallace RD and Culpepper AS, 2011. Multiple resistance in Palmer Amaranth to Glyphosate and Pyrithiobac confirmed in Georgia. Weed Sci, 59: $321-325$

Sparks TC and Nauen R, 2015. IRAC: Mode of action classification and insecticide resistance management. Pestic Biochem and Physiol, 121: 122-128, doi: http:// dx.doi.org/10.1016/j.pestbp.2014.11.014

Sparks TC, Watson GB, Loso MR, Geng C, Babcock JM et al., 2013. Sulfoxaflor and the sulfoximine insecticides: Chemistry, mode of action and basis for efficacy on resistant insects. Pestic Biochemi Physiol, 107: 1-7, Doi: http://dx.doi.org/10.1016/ j.pestbp.2013.05.014

Staub T and Sozzi D, 1984. Fungicide resistance: A continuing challenge. Plant Dis, 68: 10261031 
Steffens JJ, Pell EJ and Tien M, 1996. Mechanisms of fungicide resistance in phytopathogenic fungi. Curr Opin Biotechnol, 7: 348-355

Subash SP, Prem C, Pavithra S, Balaji SJ and Suresh P, 2017. Pesticide Use in Indian Agriculture: Trends, Market Structure and Policy Issues. Policy Brief 43, ICAR - National Institute of Agricultural Economics and Policy Research, December, 2017. Available in https://www.researchgate.net/publication/ 323028689 [28 Aug, 2019]

Sweileh WM, Sawalha AF, Al-Jabi SW, Zyoud SH, Shraim NY et al., 2016. A bibliometric analysis of literature on malaria vector resistance: (1996-2015). Global Health, 12: 76, doi: 10.1186/s12992-016-0214-4

Tabashnik BE, Mota-Sanchez D, Whalon ME, Hollingworth RM and Carrière Y, 2014. Defining Terms for Proactive Management of Resistance to Bt Crops and Pesticides. J Econ Entomol, 107(2): 496-507, doi: http:/ /dx.doi.org/10.1603/EC13458

Tello V, Diaz L and Sanchez M, 2013. Side effects of the natural pesticide Spinosad (GF-120 Formulation) on Eretmocerus paulistus (Hymenoptera: Aphelinidae), a parasitoid of the whitefly Aleurothrixus floccosus (Hemiptera: Aleyrodidae), under laboratory conditions. Cien Inv Agr, 40(2): 407-417, http://dx.doi.org/10.4067/S071816202013000200015
US EPA, 2017. Slowing and Combating Pest Resistance to Pesticides. Available in https:/ /www.epa.gov/pesticide-registration/ slowing-and-combating-pest-resistancepesticides [10 Oct, 2019]

Vila-Aiub MM, Goh SS, Gaines TA, Han H, Busi R et al., 2014. No fitness cost of glyphosate resistance endowed by massive EPSPS gene amplification in Amaranthus. Planta, 239(4): 793-801

WHO: World Health Organization, 2014. Antimicrobial Resistance: Global Report on Surveillance. WHO, Geneva

Yadav S and Dutta S, 2019. A study of pesticide consumption pattern and farmer's perceptions towards pesticides: A Case of Tijara Tehsil, Alwar (Rajasthan). Int J Curr Microbiol App Sci, 8(4): 96-104

Ying X, Chi Q, Ge M, Liu Y, Chen L et al., 2019. Analysis of UB and L40, related to deltamethrin stress in the diamondback moth, Plutella xylostella (L.). Gene, 684: 149-153, doi: https://doi.org/10.1016/ j.gene. 2018.10.083

Yu Q and Powles S, 2014. Metabolism based herbicide resistance and cross resistance in crop weeds: A threat to herbicide sustainability and global crop production. Plant Physiol, 166: 11061118 